\title{
ELEVADAS CONCENTRAÇÕES DE METAIS EM ÁGUAS DO CÓRREGO SÃO JOSÉ, CASCAVEL (PR), E POSSÍVEIS RISCOS À SAÚDE
}

\section{Phallcha Luízar Obregón}

Doutora em Saúde Pública pela Universidade de São Paulo (USP). Docente no curso de Medicina da Universidade Estadual do Oeste do Paraná (UNIOESTE) Brasil.

\section{Fernando Rodolfo Espinoza Quiñones}

Doutor em Física Nuclear pelo Instituto de Física da Universidade de São Paulo (USP-Brasil). Docente da Universidade Estadual do Oeste do Paraná (UNIOESTE), Toledo, Brasil.

\section{Emanuelle Bianchi da Silva}

Discente do Curso de Medicina, Brasil.

Clovis Casagrande Junior

Discente do Curso de Medicina, Brasil
RESUMO: O objetivo deste estudo foi avaliar a qualidade da água do córrego São José, afluente do rio Boi Piguá, e seu risco à saúde da população do entorno do Aterro Sanitário Municipal da cidade de Cascavel (PR). Foram monitorados parâmetros físico-químicos e elementos em nível de traço, em quatro pontos ao longo do córrego São José durante vinte e quatro meses. Também foi aplicado questionário à população, que mantém contato com a água desse córrego. Foram detectadas concentrações dos elementos químicos As, $\mathrm{Pb}, \mathrm{Cr}, \mathrm{Cu}, \mathrm{Hg}$, Se e $\mathrm{V}$ em desconformidade aos limites máximos permitidos pela legislação ambiental, além dos valores de oxigênio dissolvido e condutividade elétrica. Verificou-se que a qualidade da água foi influenciada negativamente pela presença do aterro sanitário. Além disso, doenças gastrointestinais, dermatites e alterações organolépticas na água foram relatadas pela comunidade. Problemas de saúde da população no entorno podem estar possivelmente vinculados ao uso das águas do córrego.

PALAVRAS-CHAVE: Contaminação Ambiental; Grupos de Risco; Metais; Vigilância em Saúde Pública.

\section{HIGH METAL CONCENTRATIONS IN THE STREAM SÃO JOSÉ, CASCAVEL (PR) AND POSSIBLE HEALTH RISKS}

\begin{abstract}
The water quality of the stream São José, an effluent of the river Boi Piguá, and health risks to the population living around the Municipal Landfill in Cascavel, Brazil, is assessed. Physical and chemical parameters and trace elements were monitored at four sites throughout the stream São José during twenty-four months. A questionnaire was applied to people who were in contact with water from the stream. Concentrations of the chemical elements $\mathrm{As}, \mathrm{Pb}, \mathrm{Cr}, \mathrm{Cu}$, $\mathrm{Hg}$, Se and $\mathrm{V}$ were detected, in non-compliance with maximum limits permitted by environmental legislation, coupled to rates of dissolved oxygen and electric conductivity. Water quality was negatively affected by the proximity of the sanitary landfill. Gastrointestinal diseases, dermatitis and organoleptic modifications in the water were reported. Health problems of the people living in the area may be related to the use of the stream water.
\end{abstract}

KEY WORDS: Contamination of the environment; Risk groups; Metals; Vigilance in public health. 


\section{INTRODUÇÃO}

Nos dias de hoje, a água desempenha papel-chave para o desenvolvimento da agricultura e da indústria, além de exercer grande influência na qualidade de vida dos organismos vivos presentes nos compartimentos aquáticos e das pessoas quando fazem uso daquela em suas diferentes atividades. Entretanto, as atividades agrícolas e industriais têm contribuído para a depreciação da qualidade de águas nos rios e córregos quando suas águas residuais são despejadas sem tratamento adequado nos corpos hídricos. Nesse sentido, há o potencial de contaminação ambiental e humana por diferentes agentes, com impacto em todo o ecossistema, incluindo os seres humanos.

Existe uma preocupação com a problemática que envolve a água, em virtude de sua importância na vida de qualquer organismo vivo, sendo um recurso indispensável à sobrevivência humana. Contudo, devido à crescente urbanização, o aumento da demanda pela água e a ampliação dos contaminantes de recursos hídricos, a disponibilidade deste recurso de forma potável e segura para a saúde humana tem se tornado um desafio cada vez maior ${ }^{1}$. Assim, o avanço da contaminação ambiental pode se refletir em um problema de Saúde Pública.

De acordo com a Organização Mundial da Saúde (OMS) e do Fundo das Nações Unidas para a Infância (UNICEF), bilhões de pessoas têm acesso a serviços básicos de água e saneamento desde 2000. Entretanto, aproximadamente 160 milhões de pessoas utilizam águas superficiais não tratadas (lagos, rios, córregos, canais de irrigação) e, dessas, 150 milhões vivem em zonas rurais ${ }^{2}$. Em particular, o Brasil possui a maior disponibilidade de água do planeta e a maioria dos mananciais de abastecimento é superficial, tais como rios, riachos, igarapés, barragens, açudes, poços abertos, entre outros. Entretanto, esses mananciais são extremamente suscetíveis a todo tipo de contaminação, tais como os despejos de esgoto doméstico e efluentes industriais, além de contaminantes naturais por erosão dos solos e/ou desgaste de rochas ${ }^{3}$. Desta forma, normas sobre a qualidade da água foram estabelecidas pela resolução n. 357/2005 do Conselho Nacional do Meio Ambiente (CONAMA) ${ }^{4}$, e por outra na área da saúde ${ }^{5}$, para que se mantivesse um padrão míni- mo de qualidade da água com o menor impacto possível de contaminantes. Nesse sentido, a qualidade da água, para ser considerada adequada em determinada atividade, deve atender aos parâmetros físico-químicos, elementares e biológicos máximos permissíveis na água. Além disso, pode servir de instrumento nas ações de controle e prevenção da contaminação das águas e minimização dos riscos à saúde.

Atualmente, o número de recursos hídricos contaminados é desconhecido no Brasil, portanto, há a necessidade de mais estudos a esse respeito. No Paraná, segundo o sistema de vigilância em saúde, 99,8\% de seus municípios realizam ações de vigilância no que se refere à qualidade da água para o consumo humano, entretanto, as informações em relação às áreas rurais são escassas ${ }^{6}$.

Trabalhos de monitoramento da qualidade das águas de córregos urbanos e rurais têm reportado alterações nas propriedades físico-químicas ${ }^{7-10}$, presença de agrotóxicos $^{11,12}$ e metais $^{13,14}$. Tais dados estão em oposição às recomendações da resolução 357/2005 do CONAMA . Além disso, foram também reportados problemas ambientais quanto às propriedades das águas em ambientes aquáticos sob a influência de aterros sanitários ativos ou inativos. Nos aterros sanitários, a decomposição do material sólido, orgânico e/ou inorgânico, disposto em valas, gera o chorume que é fonte de contaminação. É reconhecido que o chorume apresenta elevada carga de contaminantes inorgânicos e orgânicos, voláteis, pesticidas, solventes e metais pesados ${ }^{15,16}$, os quais podem comprometer a qualidade do solo, da água e do ar. Isso representa riscos ao meio ambiente e, por conseguinte, à saúde pública.

$\mathrm{Na}$ literatura, estudos têm apontado a preocupação latente em relação à população que mora nas proximidades de córregos contaminados ${ }^{8,13}$, a qual pode ser atingida direta ou indiretamente pela poluição dos cursos d'água. A saúde dessas pessoas pode ser diretamente afetada pela contaminação, uma vez que a exposição é mais duradoura em relação a trabalhadores que ficam expostos apenas no período do trabalho. Em termos de saúde, um grande número de doenças de veiculação hídrica tem sido associado à contaminação das águas ${ }^{1,5}$, geralmente relacionadas à presença de bactérias. No entanto, o desenvolvimento de doenças agudas e/ou crônicas relacio- 
nadas à exposição de compostos químicos ainda não está muito bem esclarecido ${ }^{13,17-18}$, logo, são necessários mais estudos sobre $\mathrm{o}$ assunto.

O objetivo deste estudo foi avaliar a qualidade da água do córrego São José, afluente do rio Boi Piguá, e seu risco à saúde da população do entorno do Aterro Sanitário Municipal da cidade de Cascavel (PR).

\section{METODOLOGIA}

Foi desenvolvido um estudo descritivo e quantitativo, de 2015 a 2017, no que tange à avaliação da qualidade da água a partir dos parâmetros físico-químicos e concentrações de metais, além de entrevistas aos moradores no entorno do Aterro Sanitário Municipal de Cascavel, localizado à margem direita do córrego São José que, por sua vez, é um dos afluentes do rio Boi Piguá, no distrito de Espigão Azul. Sua foz fica no Rio Azul, que é um afluente à margem esquerda do Rio Piquiri.

A zona em estudo compreende uma área de $143,17 \mathrm{~km}^{2}$, ou seja, 6,8\% do território municipal de Cascavel. As principais atividades de uso e ocupação do solo da bacia são a agricultura e a pecuária, além da cobertura florestal. Devido à proximidade deste córrego com o aterro sanitário, existe a possibilidade de contaminação superficial do solo, água e sedimento do córrego e das minas de água, com o percolado e o chorume das lagoas do aterro sanitário. O córrego, cujas águas são utilizadas para a criação de animais domésticos e a agricultura familiar, tem importante papel na vida da população no entorno do aterro sanitário. O turismo local atrai moradores da cidade de Cascavel e região nos finais de semana para o lazer e recreação no córrego.

Qualidade da água: as informações sobre a qualidade da água foram obtidas a partir das medidas de uma série de parâmetros físico-químicos e da concentração de elementos químicos identificados. Para tanto, foram escolhidos quatro pontos de coleta, utilizando-se como critérios as contribuições dos principais afluentes ao córrego, a relação das ações da população rural, além de suas condições físicas e facilidade de acesso.

A região em estudo está destacada no mapa, como mostrado na Figura 1, cujas coordenadas geográficas dos pontos de coleta estão resumidas na Tabela 1 . O primeiro ponto de coleta (P1) é localizado próximo ao local onde a comunidade cascavelense realiza atividades de pesca nos finais de semana e feriados. O segundo e terceiro pontos de coleta (P2 e P3), de acesso mais restrito, encontram-se no meio da mata ciliar e perto de minas de águas, além de receberem influência superficial das lagoas do aterro sanitário principalmente nos dias de chuva. O quarto e último ponto de coleta (P4) localiza-se a jusante dos outros três pontos de coleta, confluindo os efeitos naturais do próprio curso natural de água e de outras fontes.

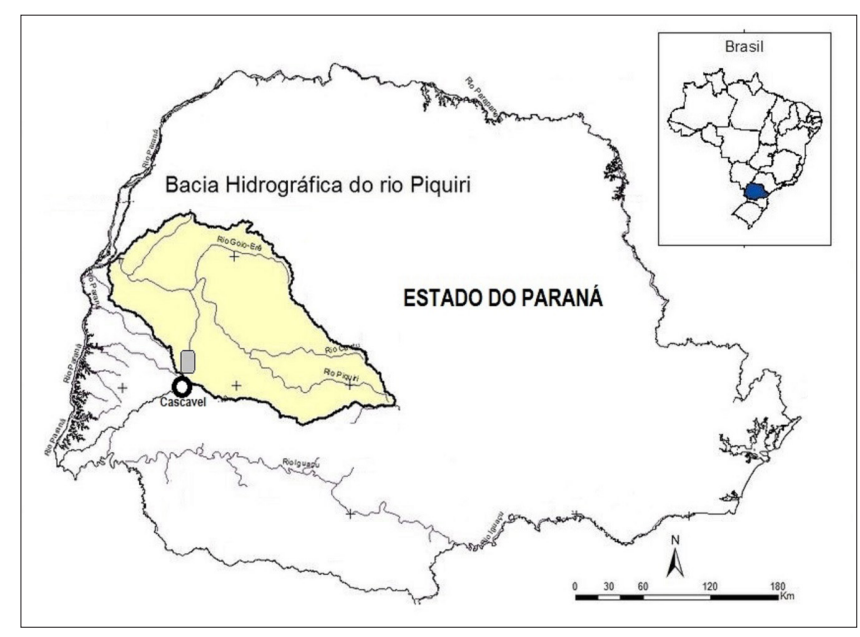

Figura 1. A região demarcada em estudo, na cor cinza, e a área rural do município de Cascavel, dentro da bacia hidrográfica do Rio Piquiri na região Oeste do Estado do Paraná. Fonte: SUDERHSA, 2007.

Tabela 1. Coordenadas geográficas dos pontos de coleta

\begin{tabular}{ccc}
\hline Pontos de coleta & Latitude & Longitude \\
\hline P1 & $24^{\circ} 51^{\prime} 15.3^{\prime \prime} \mathrm{S}$ & $53^{\circ} 29^{\prime} 57.9^{\prime \prime} \mathrm{O}$ \\
P2 & $24^{\circ} 51^{\prime} 13.6^{\prime \prime} \mathrm{S}$ & $53^{\circ} 29^{\prime} 58.5^{\prime \prime} \mathrm{O}$ \\
P3 & $24^{\circ} 51^{\prime} 12.9^{\prime \prime} \mathrm{S}$ & $53^{\circ} 29^{\prime} 57.5^{\prime \prime} \mathrm{O}$ \\
P4 & $24^{\circ} 51^{\prime} 10.3^{\prime \prime} \mathrm{S}$ & $53^{\circ} 30^{\prime} 00.2^{\prime \prime} \mathrm{O}$ \\
\hline
\end{tabular}

As amostras de água do córrego São José foram coletadas mensalmente no período de julho de 2015 a junho de 2017. Recipientes plásticos, de $1 \mathrm{~L}$, previamente lavados com solução de ácido nítrico, diluída a $10 \%$ e rotulados para cada ponto de coleta foram utilizados para fazer as coletas de água de rio. Foram feitas coletas de água tanto para análises físico-químicas da água como para análises espectrométricas de elementos químicos.

Para análises espectrométricas e preservação de amostras, foram adicionados $2 \mathrm{~mL}$ de $\mathrm{HNO}_{3}$ por litro de 
amostra de água. Todas as amostras foram acondicionadas em caixas térmicas e encaminhadas, no dia da coleta, ao Laboratório de Análise e Pesquisas Ambientais (LAPA) do Núcleo de Biotecnologia e Desenvolvimento de Processos Químicos (NBQ) do Campus da Universidade Estadual do Oeste do Paraná (UNIOESTE) de Toledo. In loco, com uma sonda multiparamétrica (Hanna, modelo HI 9828/4-01), foram realizadas as medidas de temperatura ambiente, temperatura da água, o pH da água, a concentração de oxigênio dissolvido (OD), a condutividade elétrica (CE) e a quantidade de sólidos totais suspensos (STS).

No laboratório, a medida da turbidez e a demanda química de oxigênio (DQO) foram medidas, além das concentrações de metais por análise espectrométrica. Foi utilizado o espectrômetro de Fluorescência de Raios X por reflexão total - TXRF (Bruker, modelo S2-PICOFOX) na identificação e quantificação de elementos químicos dissolvidos em água do córrego. O método do padrão interno foi aplicado para quantificação elementar, tal como foi feito no estudo conduzido por Obregón et al ${ }^{14}$. A metodologia de análise por TXRF foi validada utilizando-se material de referência certificado (Bruker, Kraft XIII), contendo uma série de dez elementos à concentração de $1 \mathrm{mgL}^{-1}$.

Entrevistas com os moradores: um questionário semiestruturado foi aplicado, entre os meses de janeiro e fevereiro de 2017, para o levantamento de dados a respeito da população com residência no entorno do aterro sanitário do município de Cascavel, principalmente no que tange à saúde e às questões sanitárias. Como critérios de inclusão para o estudo foram considerados: (1) ter residência na área de estudo, (2) ter idade mínima de 18 anos, (3) aceitar participar do estudo. O instrumento utilizado foi composto por questões relacionadas aos aspectos socioeconômicos e à percepção de doenças associadas à qualidade do ambiente aquático. Os aspectos éticos de acordo com as normativas vigentes foram observados e o estudo foi aprovado pelo Comitê de Ética em Pesquisa da Universidade Estadual do Oeste do Paraná sob o parecer 1.665.073/2016.

Análise dos dados: um único banco de dados do Excel (Microsoft Corporation) foi construído e os dados foram organizados. Foram estimados a média, o des- vio padrão, o valor mínimo e máximo de cada parâmetro físico-químico e de elementos químicos, os quais foram comparados com o valor máximo permitido pela resolução 357/2005 do CONAMA ${ }^{4}$. A frequência relativa de cada variável foi calculada para a análise das entrevistas.

\section{RESULTADOS}

FÍSICO-QUÍMICOS

As médias bem como os valores mínimo e máximo dos parâmetros físico-químicos avaliados, para cada ponto de coletas, estão apresentados na Tabela 2. De acordo com a Tabela 2, os valores médios de $\mathrm{pH}$, turbidez, DQO e sólidos dissolvidos totais para os quatro pontos de coleta se encontraram abaixo dos valores recomendados pelo CONAMA ${ }^{4}$. Entretanto, os valores de oxigênio dissolvido na água no ponto $\mathrm{P} 3$ encontram-se em desconformidade com o valor máximo $\left(\mathrm{O}_{2}>5 \mathrm{mgL}^{-1}\right)$ estabelecido pelo CONAMA ${ }^{4}$. Além disso, os dados para a condutividade elétrica da água no ponto P3 estão em desconformidade com os valores máximos recomendados pela Companhia de Tecnologia e Saneamento Ambiental - CETESB (Secretaria do Meio Ambiente de São Paulo, 2009) ${ }^{19}$, os quais sugerem um ambiente impactado.

Tabela 2. Valores médios, mínimo e máximo dos parâmetros físico-químicos da água no córrego São José, Cascavel (PR), no período 2015-2017

\begin{tabular}{|c|c|c|c|c|c|}
\hline \multirow{2}{*}{ PARÂMETROS } & \multicolumn{4}{|c|}{ Pontos de Coleta } & \multirow{2}{*}{ CONAMA } \\
\hline & P1 & P2 & P3 & P4 & \\
\hline \multirow[b]{2}{*}{$\begin{array}{l}\text { Temperatura } \\
\text { da água }\left({ }^{\circ} \mathrm{C}\right)\end{array}$} & 20,2 & 20,7 & 19,8 & 20,2 & \multirow[b]{2}{*}{-} \\
\hline & $\begin{array}{c}17,9- \\
21,9\end{array}$ & $\begin{array}{c}19,5- \\
21,9\end{array}$ & $\begin{array}{c}15,7- \\
22,2\end{array}$ & $\begin{array}{l}17,2- \\
221,9\end{array}$ & \\
\hline \multirow{2}{*}{$\begin{array}{l}\text { Temperatura } \\
\text { do } \operatorname{ar}\left({ }^{\circ} \mathrm{C}\right)\end{array}$} & 19,7 & 19,8 & 19,7 & 19,7 & \multirow[b]{2}{*}{-} \\
\hline & $\begin{array}{c}15,7- \\
22\end{array}$ & $\begin{array}{c}15,7- \\
21,5\end{array}$ & $\begin{array}{l}15,3- \\
22,4\end{array}$ & $16-22$ & \\
\hline \multirow[b]{2}{*}{$\mathrm{pH}$} & 6,0 & 6,1 & 6,6 & 5,8 & \multirow[b]{2}{*}{$6-9$} \\
\hline & $\begin{array}{l}4,6- \\
8,9\end{array}$ & $\begin{array}{c}4,5- \\
8,8\end{array}$ & $\begin{array}{l}5,3- \\
8,1\end{array}$ & $\begin{array}{l}4,4- \\
8,4\end{array}$ & \\
\hline
\end{tabular}


Conclusão

\begin{tabular}{|c|c|c|c|c|c|}
\hline \multirow{2}{*}{ PARÂMETROS } & \multicolumn{4}{|c|}{ Pontos de Coleta } & \multirow{2}{*}{ CONAMA } \\
\hline & P1 & P2 & P3 & P4 & \\
\hline \multirow[b]{2}{*}{$\begin{array}{l}\text { Oxigênio dis- } \\
\text { solvido }\left(\mathrm{mgL}^{-1}\right)\end{array}$} & 7,6 & 6,7 & 3,8 & 7,5 & \multirow[b]{2}{*}{$>5$} \\
\hline & $\begin{array}{l}2,8- \\
12,4\end{array}$ & $\begin{array}{l}1,9- \\
12,8\end{array}$ & $\begin{array}{c}1,3- \\
5,9\end{array}$ & $1,5-20$ & \\
\hline \multirow{2}{*}{$\begin{array}{l}\text { Condutividade } \\
\text { elétrica }(\mu \mathrm{S} / \\
\mathrm{cm})\end{array}$} & 13,8 & 16,4 & 347,4 & 21,2 & \multirow[b]{2}{*}{$<100^{*}$} \\
\hline & 9.24 & $12 \cdot 24$ & $\begin{array}{l}41- \\
1938\end{array}$ & $13-53$ & \\
\hline \multirow{2}{*}{$\begin{array}{l}\text { Turbidez } \\
\text { (NTU) }\end{array}$} & 4,0 & 3,0 & 6,9 & 4,4 & \multirow[b]{2}{*}{$<100$} \\
\hline & $\begin{array}{l}0,9- \\
13,1\end{array}$ & $\begin{array}{l}1,0- \\
10,7\end{array}$ & $\begin{array}{l}1,0- \\
22,2\end{array}$ & $\begin{array}{l}0,4- \\
12,9\end{array}$ & \\
\hline \multirow[b]{2}{*}{$\mathrm{DQO}\left(\mathrm{mgL}^{-1}\right)$} & 9,0 & 10,3 & 27,3 & 9,8 & \multirow[b]{2}{*}{$<150$} \\
\hline & $\begin{array}{l}6,1- \\
14,1\end{array}$ & $\begin{array}{l}8,1- \\
13.1\end{array}$ & $\begin{array}{r}23,1- \\
34,4\end{array}$ & $\begin{array}{l}6,1- \\
17.8\end{array}$ & \\
\hline \multirow{2}{*}{$\begin{array}{l}\text { Sólidos dis- } \\
\text { solvidos totais } \\
(\mathrm{mg} / \mathrm{L})\end{array}$} & 6,8 & 8,2 & 118,3 & 10,6 & \multirow[b]{2}{*}{$<500$} \\
\hline & $5 \cdot 12$ & $6 \cdot 12$ & $\begin{array}{l}21- \\
683\end{array}$ & $7 \cdot 27$ & \\
\hline
\end{tabular}

*Valor CETESB.

\section{ELEMENTOS QUÍMICOS}

Os valores médios e desvios padrões das concentrações dos elementos químicos em estudo para os quatro pontos de coleta estão resumidos na Tabela 3. São também apresentados os valores máximos permitidos pela resolução 357/2005 do CONAMA ${ }^{4}$. Pela técnica TXRF, foram identificados dezesseis elementos químicos, nos níveis de traço $\left(\mathrm{em} \mathrm{mgL}^{-1}\right)$. Cabe destacar que os elementos químicos arsênio, chumbo, cobre, cromo, mercúrio, selênio e vanádio foram encontrados em concentrações acima do valor máximo permitido pelo CONAMA ${ }^{4}$, em todos os pontos de coleta.
Tabela 3. Valores médio, mínimo e máximo das concentrações elementares em águas do córrego São José, Cascavel (PR), no período 2015-2017

\begin{tabular}{|c|c|c|c|c|c|}
\hline \multirow{2}{*}{$\stackrel{\mathscr{0}}{:}$} & \multicolumn{4}{|c|}{ Concentração elementar $\left(\mathrm{mg} \mathrm{L}^{-1}\right)$} & \multirow{2}{*}{ 节 } \\
\hline & P1 & $\mathbf{P 2}$ & P3 & P4 & \\
\hline \multirow[t]{2}{*}{ As } & 0,16 & 2,23 & 1,32 & 0,23 & 0,033 \\
\hline & 0,13-0,21 & $0,17-4,29$ & $0,09-2,48$ & $0,15 \cdot 0,42$ & \\
\hline \multirow[t]{2}{*}{$\mathrm{Ca}$} & 2,47 & 1,47 & 1,78 & 2,40 & - \\
\hline & $0,03-14,3$ & $0,03-1,3$ & $0,02-14$ & $0,04-14,8$ & \\
\hline \multirow[t]{2}{*}{$\mathbf{P b}$} & 0,05 & 0,05 & 0,13 & 0,03 & 0,033 \\
\hline & $0,05-0,05$ & $0,02-0,08$ & $0,12-0,15$ & $0,01 \cdot 0,05$ & \\
\hline \multirow[t]{2}{*}{ Co } & 0,28 & 0,03 & 0,06 & 0,08 & 0,2 \\
\hline & $0,006-1,43$ & $0,02-0,05$ & $0,02-0,14$ & $0,002-0,19$ & \\
\hline \multirow[t]{2}{*}{$\mathrm{Cu}$} & 0,05 & 0,04 & 0,08 & 0,25 & 0,013 \\
\hline & $0,02-0,12$ & $0,02-0,10$ & $0,01-0,41$ & $0,02-2$ & \\
\hline \multirow[t]{2}{*}{$\mathrm{Cr}$} & 1,11 & 0,99 & 0,40 & 6,96 & 0,05 \\
\hline & $0,3 \cdot 3,51$ & $0,42-3,23$ & $0,16-0,97$ & $0,43 \cdot 56,7$ & \\
\hline \multirow[t]{2}{*}{ Sn } & 0,12 & 0,03 & 0,03 & 0,04 & - \\
\hline & $0,003-0,94$ & $0,007-0,07$ & $0,002-0,08$ & $0,003-0,12$ & \\
\hline \multirow[t]{2}{*}{$\mathrm{Sr}$} & 0,09 & 0,02 & 0,03 & 0,08 & - \\
\hline & $0,008 \cdot 0,61$ & $0,01-0,03$ & $0,01-0,08$ & $0,01-0,37$ & \\
\hline \multirow[t]{2}{*}{$\mathrm{Fe}$} & 0,15 & 0,12 & 0,09 & 0,2 & 5 \\
\hline & $0,007-0,52$ & $0,01-0,58$ & $0,009-0,72$ & $0,007 \cdot 1,3$ & \\
\hline \multirow[t]{2}{*}{$\mathrm{Mg}$} & 0,67 & 0,41 & 0,45 & 0,71 & - \\
\hline & $0,001 \cdot 3,68$ & $0,01-3,5$ & $0,002 \cdot 3,7$ & $0,002-4,5$ & \\
\hline \multirow[t]{2}{*}{$\mathrm{Mn}$} & 0,04 & 0,02 & 0,02 & 0,05 & 0,5 \\
\hline & $0,004-0,24$ & $0,007-0,03$ & $0,005-0,05$ & $0,007-0,10$ & \\
\hline \multirow[t]{2}{*}{$\mathrm{Hg}$} & 0,005 & 0,009 & 0,007 & 0,090 & 0,002 \\
\hline & $0,002-0,008$ & 0,003-0,030 & $0,002-0,014$ & $0,002-0,610$ & \\
\hline \multirow[t]{2}{*}{ K } & 0,41 & 0,42 & 0,23 & 1,96 & - \\
\hline & $0,001-0,73$ & $0,27-0,71$ & $0,03-0,56$ & $0,001-3,93$ & \\
\hline \multirow[t]{2}{*}{$\mathrm{Se}$} & 3,0 & 0,2 & 1,2 & 1,1 & 0,05 \\
\hline & $0,08-9,93$ & $0,05-0,5$ & $0,28-2,21$ & $0,26-1,9$ & \\
\hline \multirow[t]{2}{*}{$\mathbf{v}$} & 3,24 & 0,25 & 0,38 & 0,9 & 0,1 \\
\hline & $0,07-18,2$ & $0,08 \cdot 0,64$ & $0,04-1,05$ & $0,07 \cdot 3,3$ & \\
\hline \multirow[t]{2}{*}{$\mathrm{Zn}$} & 0,05 & 0,12 & 0,04 & 0,03 & 5 \\
\hline & $0,04-0,06$ & $0,04-0,35$ & $0,01-0,05$ & $0,02-0,05$ & \\
\hline
\end{tabular}

\section{ENTREVISTAS COM A POPULAÇÃO}

Nove pessoas foram entrevistadas na área em estudo, correspondendo a cinco propriedades próximas ao córrego. Também, $66,7 \%$ dos entrevistados referiram idade maior de 50 anos; 55,6\% são mulheres; 88,9\% têm o $1^{\circ}$ grau incompleto de escolaridade e 44,4\% têm renda familiar de dois salários mínimos. 
Em relação ao saneamento e esgoto, 88,9\% referiram utilizar água de minas e 100\% utilizam fossas, 55,6\% referiram queimar o lixo produzido. Mais da metade $(66,7 \%)$ dos indivíduos referiu ter presenciado a morte de animais por causa desconhecida dentro de sua propriedade, sendo esses: peixes (66,7\%), pássaros (33,3\%), sapos $(16,7 \%)$, animais domésticos $(66,7 \%)$, ovelhas $(16,7 \%)$, cabritos (16,7\%) e frangos (16,7\%).

A água utilizada pelos animais é proveniente do córrego e das minas de água. A horta familiar é comum entre os participantes, cuja água utilizada para irrigação é proveniente de minas em $88,9 \%$ dos casos. O uso de agrotóxicos foi referido por 33,3\% dos participantes. Em duas propriedades, houve o relato de comprometimento da lavoura e doença de animais devido à contaminação do solo e água com o vazamento de chorume das lagoas do aterro sanitário em épocas de chuva. A percepção dos entrevistados em relação ao córrego é apresentada na Tabela 4, onde os resultados mostram que mudanças organolépticas no córrego estão associadas à diminuição de peixes, doenças e/ou morte de animais.

Tabela 4. Impressão dos entrevistados sobre o córrego e a sua relação com os seres vivos

\begin{tabular}{|l|l|c|}
\hline Contexto & Atribuição pessoal & $\%$ \\
\hline \multirow{4}{*}{$\begin{array}{l}\text { Aspectos } \\
\text { d'água }\end{array}$} & Sabor ruim & 44,4 \\
\cline { 2 - 3 } & Cor esverdeada & 44,4 \\
\cline { 2 - 3 } & Cheiro desagradável & 88,9 \\
\cline { 2 - 3 } & longo do tempo & 88,9 \\
\cline { 2 - 3 } & Não utiliza para consumo humano & 77,8 \\
\cline { 2 - 3 } & $\begin{array}{l}\text { Uso para recreação, consumo, pesca, irri- } \\
\text { gação }\end{array}$ & 22,2 \\
\cline { 2 - 3 } & Presença de lixo no córrego & 77,8 \\
\hline \multirow{4}{*}{$\begin{array}{l}\text { O córrego e a a } \\
\text { sua influência } \\
\text { nos seres } \\
\text { vivos }\end{array}$} & $\begin{array}{l}\text { Menor quantidade de peixes com mudan- } \\
\text { ças no córrego }\end{array}$ & 22,2 \\
\cline { 2 - 3 } & Maior quantidade de vetores & 22,2 \\
\cline { 2 - 3 } & $\begin{array}{l}\text { Morte e/ou doenças em animais que usam } \\
\text { água do córrego }\end{array}$ & 22,2 \\
\cline { 2 - 3 } & $\begin{array}{l}\text { Prejuízo da lavoura por uso d'água de } \\
\text { córrego }\end{array}$ & 44,4 \\
\hline
\end{tabular}

A prefeitura não realiza medidas de limpeza no córrego para $88,9 \%$ dos entrevistados e apenas dois participantes relataram que a prefeitura desenvolveu projeto de recuperação do córrego, sendo este o fornecimento de mudas de árvores para serem plantadas às margens do mesmo.

Em relação às características do processo saúde-doença, 77,8\% afirmaram possuir alguma doença (dislipidemia, hipertensão arterial, cardiopatia). Todavia, a mesma porcentagem considera a sua saúde boa. Cerca de um quinto dos entrevistados relatou ter percebido alguma alteração no seu estado de saúde que pode estar relacionada à situação do córrego. Foram citados episódios frequentes de diarreia e de cefaleia.

A presença de doenças relacionadas à ingesta da água do córrego foi relatada pela população entrevistada, compreendendo os quadros gastrointestinais, na maioria dos casos, seguida de dermatites e cefaleias. Tais casos foram, geralmente, observados em moradores da localidade e turistas que frequentam a área. As crianças e trabalhadores rurais foram apontados como os grupos mais atingidos. Famílias com crianças que adoeceram pelo uso da água do córrego têm optado por mudar de residência quando possível e/ou utilizar água de outras fontes.

\section{DISCUSSÃO}

FÍSICO-QUÍMICO, ELEMENTOS QUÍMICOS E SAÚDE

Os resultados evidenciaram que, dos parâmetros físico-químicos avaliados, os valores de oxigênio dissolvido e a condutividade elétrica estiveram em desconformidade com aqueles valores preconizados pelo CONAMÁ . Isso ocorreu principalmente no terceiro ponto de coleta, o qual esteve sob forte influência da drenagem do chorume vazado das lagoas do aterro sanitário. O parâmetro oxigênio dissolvido é um dos critérios mais importantes, mediante o qual é feita a atribuição da qualidade das águas superficiais e, quando encontrado em baixíssimas concentrações, indica processos intensos de eutrofização, com possibilidade de ocorrência de mortandade de seres vivos do meio aquático.

De modo geral, os resultados deste estudo vêm ao encontro do descrito na literatura. Faz-se a ressalva de diferenças que podem ser explicadas pelas características locais ou regionais onde foram realizados os estudos. $\mathrm{Na}$ literatura, foram encontrados estudos que apontam 
valores em desacordo com o CONAMA ${ }^{4}$, como na bacia hidrográfica do Rio São Domingos - localizada no Noroeste do Estado do Rio de Janeiro ${ }^{20}$, onde DQO, OD, STS, alumínio, ferro, manganês e zinco foram relatados em desacordo com a legislação vigente.

Em outro estudo, no qual se avaliou as águas do Córrego Barbado em Cuiabá (MT) ${ }^{21}$, a quantidade de OD foi relatada abaixo do valor recomendado pela legislação vigente. E ainda foi relacionado com a eutrofização artificial oriunda de lançamento de esgoto doméstico. Também, o estudo realizado em 29 propriedades rurais na região de Jaboticabal (SP) ${ }^{8}$ demonstrou que $50 \%$ das amostras apresentaram bactérias coliformes, alteração na turbidez e nitrato. Ainda, um estudo realizado em vinte municípios do recôncavo baiano ${ }^{22}$ também evidenciou elevadas concentrações de coliformes, alterações de cor, turbidez e cloro residual livre com valores acima dos valores máximos permitidos pela legislação vigente.

Quanto aos elementos químicos, também denominados elementos-traço ou metais, os mesmos diferem de outros agentes tóxicos por não serem sintetizados ou destruídos pelo homem. Esses elementos podem ser resultado de fontes naturais e/ou antropogênicas e é inevitável a exposição humana a tais elementos.

Os diversos efeitos na saúde que podem ocasionar estão relacionados ao tipo de elemento químico, doses e via de exposição, tempo de exposição, características da população exposta como idade, sexo, estado nutricional, entre outros ${ }^{23,24}$. Na literatura, chumbo, mercúrio, cádmio e arsênio são os elementos químicos de maior interesse em termos de saúde pública e ocupacional e os mais estudados ${ }^{23}$. E, embora nem todos os aspectos do ambiente tenham relação com a saúde, em alguns casos, a relação não é conhecida, mas em outros é possível fazer inferências sobre essa relação.

A contaminação ambiental por metais tem sido descrita na literatura. Por um lado, estudos mostram a avaliação de impacto nos cursos d'água próximos de aterros, em diferentes contextos. Em Bauru (SP) ${ }^{25}$, um estudo apontou diferentes níveis de contaminação conforme a localização do poço estudado e as características dos resíduos depositados. No município de Três Corações, Minas Gerais ${ }^{26}$, foi avaliado o impacto sobre a qualidade da água subterrânea nas proximidades do aterro sanitário do município, os resultados mostraram fortes indícios de contaminação pelo chorume devido às alterações de algumas características da água subterrânea.

Um estudo do Córrego da Onça e de solo no Aterro II e na Sucata do Goiânia II na cidade de Goiânia (GO $)^{27}$ identificou $\mathrm{Cd}$, Ca e $\mathrm{Cu}$, K, Mn e Zn, com valores nos limites máximos permitidos pelo CONAMA ${ }^{4}$. Também em Ribeirão Preto, São Paulo16, um estudo do chorume gerado no aterro sanitário apontou valores médios de chumbo e zinco acima dos limites especificados pelo CONAMA $^{4}$.

Nesse sentido, são descritas evidências que indicam que áreas próximas a aterros apresentam níveis elevados de compostos orgânicos e metais pesados, e que populações residentes nas proximidades desses locais apresentam níveis elevados desses compostos no sangue. Esses locais são potenciais fontes de exposição para populações, tendo sido relatados riscos aumentados para diversos tipos de câncer, anomalias congênitas, baixo peso ao nascer, abortos e mortes neonatais nessas populações e populações vizinhas a esses locais ${ }^{15}$. Por outro lado, a presença de elementos-traço também tem sido descrita em cursos d'água que não se encontram sob influência de aterros, como o estudo na zona rural de Palmares do Sul (RS) ${ }^{17}$, onde foram identificados ferro em $53,8 \%$ das amostras e manganês em $92,3 \%$ das amostras, de treze poços de propriedades rurais. Tal resultado sugere que há um risco potencial não carcinogênico para a saúde de crianças relacionado ao manganês.

Um estudo na Tailândia ${ }^{28}$ avaliou a qualidade da água de doze poços de propriedades rurais e identificou risco não carcinogênico para $\mathrm{As}, \mathrm{Cu}, \mathrm{Zn}$ e $\mathrm{Pb}$ em $58 \%$ dos poços. Também o estudo em córrego urbano de Cascavel, no Paraná ${ }^{13,14}$, identificou cromo, manganês, ferro, cobre e zinco, o qual sugeriu que há risco para a população com residência nas proximidades do córrego.

No presente trabalho, entre todas as substâncias identificadas, apenas o cromo tem potencial carcinogênico ${ }^{23}$. Entretanto, a maioria desses elementos apresenta algum efeito à saúde humana. De acordo com a literatu$\mathrm{ra}^{23}$, os efeitos tóxicos provocados pela exposição a estes metais acometem todos os tecidos e sistemas do organismo humano.

Os compostos de cromo produzem efeitos cutâ- 
neos, nasais, bronco-pulmonares, renais, gastrointestinais e carcinogênicos. Os cutâneos são caracterizados por irritação no dorso das mãos e dos dedos, e podem se transformar em úlceras. As lesões nasais iniciam-se com um quadro irritativo inflamatório, supuração e formação crostosa. Em níveis bronco-pulmonares e gastrointestinais produzem irritação bronquial, alteração da função respiratória e úlceras gastroduodenais ${ }^{23}$. Quanto à ingesta de mercúrio, uma intoxicação aguda pode incluir gastrenterite e nefrotoxicidade. Já o chumbo, na forma de ingestão aguda em quantidades grandes, pode causar dor abdominal, anemia, hepatite tóxica e encefalopatia.

A exposição aguda ao arsênio produz um conjunto de sinais e sintomas multissistêmicos que surgem ao longo de horas e até semanas. Náuseas, vômitos, dor abdominal e diarreia são descritos como alguns dos efeitos gastrintestinais. A ingestão aguda de selênio causa lesão corrosiva do trato gastrointestinal superior, vômito e diarreia, hiperssalivação, odor de alho na respiração com deterioração rápida do estado mental e inquietação, e pode progredir para coma, insuficiência respiratória e morte. Contudo, em relação ao vanádio, de acordo com a literatura, não foram encontradas alterações na saúde de populações ${ }^{23}$.

\section{O CÓRREGO E A PERCEPÇÃO DA POPULAÇÃO EXPOSTA}

A percepção de indivíduos que moram nas proximidades dos rios, trabalhadores ou que frequentam aqueles espaços e utilizam o rio de diferentes formas, é descrita na literatura. Os resultados deste estudo vêm ao encontro do descrito na literatura, onde o uso das águas dos córregos foi relacionado a diversas atividades, tais como tomar banho, lavar roupa, pescar e uso para consu$\mathrm{mo}^{13,18,21}$. Ainda, dentre os diferentes problemas apontados pela população, as alterações organolépticas da água, o descarte de resíduos sólidos e esgoto, a presença de animais mortos e a presença de mau cheiro nos córregos são amplamente citados, indicando que se trata de um problema decorrente em córregos brasileiros ${ }^{13,29}$. As características apontadas pelas diferentes populações em estudo indicam que há prejuízo desses espaços à saúde, à qualidade de vida e ao trabalho da população.

Diversos trabalhos indicam a vulnerabilidade das propriedades rurais com relação à qualidade da água, no meio rural, e assinalam que o risco de ocorrência de doenças veiculadas pela água é ainda maior, principalmente pela contaminação dessas águas que, muitas vezes, são captadas em locais próximos de fontes de poluição,

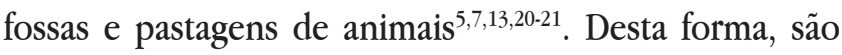
descritos trabalhos científicos que sugerem que há correlação entre as doenças e o uso da água contaminada.

Assim, em Cuiabá (MT) ${ }^{21}$, um estudo apontou que $53 \%$ dos entrevistados acreditam que contraíram algum tipo de doença decorrente da água do córrego, as quais estão associadas a náuseas, dores de cabeça e micoses de pele e dengue. Em Cascavel (PR), um estudo mostrou que $10 \%$ dos entrevistados vincularam doenças gastrointestinais e dérmicas ao uso das águas do córrego, tendo sido identificados cromo, manganês, ferro, cobre e zinco no córrego em estudo, com valores acima do permitido pela legislação vigente ${ }^{13}$.

$\mathrm{Na}$ Etiópia $^{18}$, um estudo comparou duas populações e uma delas ficava mais próxima do Rio Akaki. Os resultados desse estudo ${ }^{18}$ revelaram a presença de molibdênio, tungstênio, chumbo e mercúrio na população que fica mais próxima do Rio Akaki, quando comparada com outra população que fica mais distante do mesmo rio e $47 \%$ dos entrevistados apresentaram valores de manganês acima dos valores recomendados pela OMS. Entretanto, no estudo da Etiópia ${ }^{18}$, não houve correlação entre os níveis de metais em amostras de água e amostras clínicas, embora essas medidas tenham sido baseadas nos limiares tóxicos conhecidos e pela falta de informações sobre a toxicidade para muitos desses metais.

No presente estudo, a morbidade referida pela população entrevistada mostrou, por um lado, maior frequência de problemas de hipertensão arterial, a qual é condizente com a morbidade descrita em nível nacional onde predominam as doenças crônicas ${ }^{1}$. No entanto, deve-se ressaltar que as alterações na qualidade da água do córrego e a morbidade referida pela população relacionada com a ingesta da água e/ou contato com a água do córrego sugerem contaminação da água.

A morte dos animais e as perdas de cultivo ao longo dos anos podem indicar que há contaminação da água e do solo. Nesse sentido, a contaminação por metais pode estar relacionada à ocorrência de transtornos diges- 
tivos. Assim, embora os resultados não permitam afirmar doenças com a presença de metais identificados no córrego, não se descarta a possível influência desses metais na morbidade da população exposta. A população em estudo pode ser considerada como exposta a tais substâncias.

De acordo com o Ministério da Saúde ${ }^{1}$, uma população é considerada como exposta se existiu, existe ou existirá uma rota de exposição completa que ligue o contaminante químico de interesse com a população receptora. A definição não remete à concentração no organismo ou presença de sinais e sintomas.

A rota de exposição é composta pelos seguintes elementos: fonte de contaminação e/ou compartimento ambiental (água superficial, sedimento e biota), ponto de exposição (um curso da água, o córrego), a via de exposição (ingesta e contato com a pele) e população receptora (as pessoas que estão expostas ou potencialmente podem se expor aos contaminantes de interesse em um ponto de exposição). Entretanto, evidências mais fortes e confiáveis são necessárias para confirmar isto, de maneira que um estudo de acompanhamento mais intenso e prolongado torna-se necessário. Daí a necessidade de se verificar mensalmente as concentrações dos elementos nas amostras de águas, acompanhar as notificações de agravos bem como estudar outras possíveis fontes de contaminação antrópica.

\section{CONCLUSÃO}

A análise das águas do córrego São José revelou contaminação por causa provável antrópica de chumbo, arsênio, cobre, cromo, mercúrio, selênio e vanádio. Os valores encontrados estão bem acima dos valores máximos recomendados pela legislação ambiental vigente. As possíveis causas antrópicas de contaminação podem ser o chorume, não tratado e proveniente das lagoas do aterro sanitário do município de Cascavel, dentre outros. Existe a possibilidade da morbidade referida pela população estar relacionada com a contaminação da água.

Posto isso, torna-se notável a necessidade de uma fiscalização permanente no que diz respeito à contaminação dos mananciais ao redor do aterro sanitário do município de Cascavel e os riscos que a presença destes metais pesados na natureza oferecem à saúde do homem e dos animais. Recomendam-se, também, a continuidade do monitoramento da qualidade da água deste córrego, a inclusão de parâmetros biológicos bem como a análise de agrotóxicos, visto que a região de Cascavel está entre uma das que mais utilizam defensivos agrícolas no planeta.

\section{AGRADECIMENTOS}

À Fundação Araucária e à Universidade Estadual do Oeste do Paraná (UNIOESTE) pelas bolsas de iniciação científica concedidas.

\section{REFERÊNCIAS}

1. Ministério da Saúde (BR). Secretaria de Vigilância em Saúde. Departamento de Análise de Situação em Saúde. Saúde Brasil 2007: uma análise da situação de saúde. Brasília (DF): Ministério da Saúde; 2007. $641 \mathrm{p}$.

2. United Nations Children's Fund; World Health Organization. Progress in drinking water, and sanitation and hygiene. 2017 update and SDH baselines. Geneva: WHO/UNICEF; 2017. 110p.

3. Ministério da Saúde (BR). Análise de indicadores relacionados à água para consumo humano e doenças de veiculação hídrica no Brasil, ano 2013, utilizando a metodologia da matriz de indicadores da Organização Mundial da Saúde. Brasília (DF): Ministério da Saúde; 2015. 37p.

4. Brasil. Lei $n^{0}$. 357, de 17 de março de 2005. Dispõe sobre a classificação dos corpos de água e diretrizes ambientais para o seu enquadramento, bem como estabelece as condições e padrões de lançamento de efluentes, e dá outras providências. Conselho Nacional do Meio Ambiente - CONAMA. Diário Oficial da União, Brasília, 18 mar. 2005. p. 58-63.

5. Ministério da Saúde (BR). Secretaria de Vigilância em Saúde. Boas práticas no abastecimento de água: procedimentos para a minimização de riscos à saúde. Brasília (DF): Ministério da Saúde; 2006. 252p.

6. Ministério da Saúde (BR). Sistema nacional de vigi- 
lância em saúde. Relatório de situação no Paraná. Brasília: Ministério da Saúde; 2011. 35p.

7. Sampaio CF, Segura-Munõz SI. Qualidade físico-química e microbiológica da água para o consumo humano e a relação com a saúde: estudo em uma comunidade rural no estado de São Paulo. Mundo Saúde. 2011; 35 (1): 98-104.

8. Satake FM, Assunção AWA, Lopes LG, Amaral LA. Qualidade da água em propriedades rurais situadas na bacia Hidrográfica do Córrego Rico, Jaboticabal - SP. Ars Vet. 2012; 28 (1): 48-55.

9. Kiel G, Brun AL, Rodrigues VP. Avaliação microbiológica de água de consumo em propriedades rurais no município de Cascavel-PR, Brasil. Biodiversidade. 2012; 2 (1): 131-134.

10. Stolf DF, Molz S. Avaliação microbiológica da água utilizada para consumo humano em uma propriedade rural de Taió - SC. Saúde Meio Ambient. 2017; 6 (1): 96-106.

11. Moreira JC, Peres F, Simões AC, Pignati WA, Dores EC, Vieira SN, Strüssmann C, Mott T. Contaminação de águas superficiais e de chuva por agrotóxicos em uma região do estado do Mato Grosso. Ciência Saúde Col. 2012; 17 (6): 1557-1568.

12. Silva MR, Campos ACE, Bohm FZ. Agrotóxicos e seus impactos sobre ecossistemas aquáticos continentais. SaBios: Rev Saúde e Biol. 2013; 8 (2): 46-58.

13. Obregón PL, Espinoza-Quiñones FR, Lopes IBS. (2017). Análise de morbidade de população residente na bacia do córrego Bezerra com evidências de poluição por metais, Cascavel - PR. Espaço para a saúde - Revista Saúde Pública do Paraná. 2017; 18 (1): 117-128.

14. Obregón PL, Espinoza-Quinones FR, Módenes NA. Water quality monitoring of the Bezerra river Cascavel/Brazil using SR-TXRF technique. J. Chem. Eng. 2014; 8: 587-595.

15. Gouveia N. Resíduos sólidos urbanos: impactos socioambientais e perspectiva de manejo sustentável com inclusão social. Cien Saude Col. 2012; 17 (6): 1503-1510.

16. Celere MS, Oliveira AS, Trevilato TMB, Segura-Muñoz SI. Metais presentes no chorume coletado no aterro sanitário de Ribeirão Preto, São Paulo, Brasil, e sua relevância para saúde pública. Cad. Saúde Pública, Rio de Janeiro. 2007 abr.; 23 (4): 939-947.

17. Koller DK, Reginato PRR. Avaliação do risco à saúde humana por meio do consumo de água subterrânea contendo metais, na zona rural do município de Palmares do Sul (RS). XX Simpósio Brasileiro de Recursos Hídricos. Florianópolis. Associação Brasileira de Recursos Hídricos. Florianópolis. Anais. 2017. p: 1-8.

18. Yard E, Bayleyegn T, Abebe A, Mekonnen A, Murphy M, Caldwell KL, Luce R, Hunt DR, Tesfaye K, Abate M, Assefa T, Abera F, Habte K, Chala F, Lewis L, Kebede A. Metals Exposures of Residents Living Near the Akaki River in Addis Abeba, Ethiopia: A Cross-Sectional Study. J Environ Public Health. 2015: 935297.

19. Companhia Ambiental do Estado de São Paulo (CETESB). Significado ambiental e sanitário das variáveis de qualidade das águas e dos sedimentos e metodologias analíticas e de amostragem. São Paulo: Secretaria do Meio Ambiente/CETESB; 2009.

20. Menezes J, Prado RB, Silva Jr GC, Mansur KL, Oliveira ES. Qualidade da água superficial em área rural. CADEGEO. 2012; 3 (1): 32-43.

21. Moraleco PD, Koppe VC, Gonçalves KG, Pasa MS. Relação entre a qualidade ambiental do córrego do Barbado e a saúde da população do Jardim Renascer, Cuiabá-MT. Biodiversidade. 2014; 13 (2): 90-114.

22. Barros LSS. Mapeamento sanitário rural do Recôncavo da Bahia. Rev. Bras. Hig. Sanid. Anim. 2016; 10 (4): 604-652.

23. Agency for toxics substances \& Disease registry. Toxic substances. [acesso em 2017 Jul. 21]. Disponível em: http://www.atsdr.cdc.gov/

24. Jan AT, Azam M, Siddqui K, Ali A, Choi I, Haq QMR. Heavy metals and human health: mechanistic insight into toxicity and counter defense system of antioxidants. Int J Mol Sci. 2015; 29592-29630.

25. Mondelli G, Giacheti HL, Hamada J. Avaliação da contaminação no entorno de um aterro de resíduos sólidos urbanos com base em resultados de poços de monitoramento. Eng. Sanit. Ambient. 2016; 21 (1): 169-182.

26. Taveira MMV, Silva AM, Rodrigues LS. Impactos do aterro sanitário do município de Três Corações, Minas Gerais, na qualidade da água Subterrânea. Revis- 
ta da Universidade Vale do Rio Verde, Três Corações. 2016; 14 (1): 764-772.

27. Muro Jr A, Caetano LTL, Machado BC, Wendt EV, Muro NP. Avaliação da poluição ambiental de aquíferos e solo por metais-traço, provenientes de e-waste em Goiânia/GO. Tecnia. 2017; 2 (2): 127-151.

28. Wongsasuluk P, Chotpantarat S, Siriwong W, Robson M. Heavy metal contamination and human health risk assessment in drinking water from shallow groundwater wells in an agricultural area in Ubon Ratchathani province, Thailand. Environ Geochem Health. 2014 Feb; 36 (1): 169-182.

29. Reis JLE, Abrahão BOL, Moura BL. Os problemas do rio São Francisco na percepção de moradores de Petrolina e Juazeiro: a saúde em foco. Saúde e Pesquisa. 2017; 10 (3): 473-484.

Recebido em: 30/05/2018

Aceito em: 28/12/2018 